\title{
Justification of the need to implement intelligent warehouse systems in fish processing
}

\author{
Velizara Pencheva ${ }^{1}$, Vladimir Hvarchilkov ${ }^{2}$, Asen Asenov ${ }^{1 *}$, Ivan Beloev ${ }^{1}$, Dimitar \\ Grozev $^{1}$, Emil Yankov ${ }^{3}$, and Ivaylo Hristakov ${ }^{2}$ \\ ${ }^{1}$ Department Transport, Faculty of Transport, University of Ruse, Studentska Str.8, 7017 Ruse, \\ Bulgaria \\ ${ }^{2}$ Agricultural machinery Department, Agrarian and Industrial Faculty, University of Ruse, Studentska \\ Str.8, 7017 Ruse, Bulgaria \\ ${ }^{3}$ Materials Science and Technology Department, Faculty of Mechanical and Manufacturing, \\ University of Ruse, Studentska Str.8, 7017 Ruse, Bulgaria
}

\begin{abstract}
The paper reviews the existing state of fishing worldwide and in Bulgaria. Then the scheme is determined, according to which the live fish moves from the water basins in which it is raised and lives until it is sent to the store network and the end customers. As a result of the studies conducted, two-week points in the transitional warehouses have been identified. They are characterized by four main indexes: oxygen, temperature, Ph acidity and water level in the container. It these four are not within the determined allowances, it is possible the quality of the environment for storing the live fish to be deteriorated, which can lead to premature death of the fish. In this respect, a regression model with the four main indexes that are to be monitored and maintained within the allowance values has been created for achieving high quality of the storage environment. For the regression model has been determined a coefficient of determination $\mathrm{R}=0.9131$, and a Fisher's criterion, which is 5.0143 compared to the one in the Table -2.5802 , which shows that the model is adequate and can be used for further calculations. For the practical solution of the problem, it has been proposed to introduce an intelligent information system in the transitional warehouses for storing live fish before the end processing. The system proposed will be used to monitor and control the four main indexes and to improve the conditions for storing live fish when it is moved along the chain of fish farms to the warehouses for end processing.
\end{abstract}

\section{Introduction}

In Bulgaria in 2019, a Strategy for digitalization of agriculture in rural areas of the Republic of Bulgaria was introduced, with the aim to focus information technology in favor of agribusiness and development of rural regions [1]. The relationships, connected to ownership, organization, management, using and preserving the fish resources in the waters of the Republic of Bulgaria, the trade of fish and other water organisms, is provided for in

* Corresponding author: asasenov@uni-ruse.bg 
the Fisheries and Aquaculture Act [2]. Fish can be obtained from the sea and the rivers, where it is self-bred, or from artificial or natural reservoirs, where it is bred by specialists [3].

In freshwater fish farms are grown and caught mainly carp, catfish, silver carp, grass carp, pike, white fish, trout, etc. From the saltwater, extracted from the Black Sea, small fish like sprat, anchovy, horse mackerel and whiting are caught, as well as some larger varieties like shark, turbot and mullet, [4]. From farms to processing plants, fish is most often transported by trucks up to 3.5 tonnes, as the daily supply related to demand is not large. When transporting the fish from the reservoirs in which it is bred to the places where it will be processed and prepared for sale in the retail network, there are requirements that must be met for the conditions under which it is transported by vehicles, according to [5]. In order not to be stressed, as well as to save its life, it is necessary to comply with the requirements in [5]. They involve the quality of the water, where the fish is during transportation and later, in the water reservoirs of the processing plants. The most important factor to be considered is the presence of oxygen, carbon dioxide - $\mathrm{CO}_{2}$, level of ammonia - $\mathrm{NH}_{3}$, acidity of the environment- $\mathrm{pH}$, temperature and salinity, if it is needed for the sea fish, and the number of fish, placed in the water tank for transportation or storage. The values of the water quality parameters, according to [6], are to be: for oxygen from $70 \%-200 \%$, measured every 2 to 4 hours, for carbon dioxide - 5-10 mg / L, the level of ammonia - 0,1 mg / L. This necessitates the introduction of intelligent systems that monitor at all times the quality of the environment in which live and processed fish are located, in correspondence with the digitalization envisaged in [1]. Separately, Regulation 853 of the EC and of the Council of 2004 lays down specific hygiene rules for food of animal origin, which must be complied with by all products and their undertakings [7]. The control in the field of food safety and quality, food additives and beverages, health and animal welfare, plant protection and fertilizers, phytosanitary control, fodder, and border control of food in Bulgaria is carried out by the Bulgarian Food Safety Agency (BFSA) [8].

\subsection{Global fishing}

\subsubsection{Fishing}

Globally, the fish catch is presented in Table 1, and that in the European Union, in Table 2 [9]. The countries with the biggest catch are China - with 79,9 mln. tonnes live weight, which is $38,93 \%$ of the world catch. Then come Indonesia with $11,2 \%$, India with $5,66 \%$, and Vietnam with 3,46\%. The European Union ranks fifth with $6,8 \mathrm{mln}$. tonnes, of which 1,37 tonnes come from aquacultures and the rest is free catch. The total catch worldwide is 205,3 $\mathrm{mln}$. tonnes, of which $54,6 \%$ are from aquacultures and the rest is free catch.

The country with the biggest catch in the EU is Spain with 908 thous. tonnes free catch and 222 thous. tonnes from aquacultures. The quantity of catch in Bulgaria for 2017, according to Table 2, shows that 15751 tonnes of fish, mussels and the like are obtained from aquacultures in the fish breeding farms along the Black sea and the rivers while 8559 tonnes come from free catch from the Black sea and the river basins, one of which is the Danube. This shows that $64,8 \%$ of the fish catch comes from aquacultures.

Table 1. Main world producers catches fish and aquaculture (volume in tonnes live weight), for 2017

\begin{tabular}{|c|c|c|c|c|c|}
\hline № & Country & Catches & Aquaculture & $\begin{array}{c}\text { Total } \\
\text { production }\end{array}$ & \% Total \\
\hline 1 & China & 15576687 & 64358481 & 79935168 & $38,93 \%$ \\
\hline 2 & Indonesia & 6736280 & 15896100 & 22632380 & $11,02 \%$ \\
\hline
\end{tabular}




\begin{tabular}{|c|c|c|c|c|c|}
3 & India & 5450313 & 6182000 & 11632313 & $5,66 \%$ \\
\hline 4 & Vietnam & 3277574 & 3831241 & 7108815 & $3,46 \%$ \\
\hline 5 & EU-27 & $\mathbf{5 4 2 8 5 7 0}$ & $\mathbf{1 3 7 2 ~ 0 1 2}$ & $\mathbf{6 8 0 0 5 8 2}$ & $\mathbf{3 , 3 1 \%}$ \\
\hline 6 & United States & 5040461 & 439670 & 5480131 & $2,67 \%$ \\
\hline 7 & Russian Federation & 4878632 & 186544 & 5065176 & $2,47 \%$ \\
\hline 8 & Japan & 3274147 & 1021580 & 4295727 & $2,09 \%$ \\
\hline 9 & Peru & 4185193 & 100455 & 4285648 & $2,09 \%$ \\
\hline 10 & Bangladesh & 1801084 & 2333352 & 4134436 & $2,01 \%$ \\
\hline 11 & Philippines & 1889990 & $2237 \mathbf{7 8 7}$ & $4127 \mathbf{7 7 7}$ & $2,01 \%$ \\
\hline 12 & Norway & 2533258 & 1308634 & 3841892 & $1,87 \%$ \\
\hline 13 & South Korea & 1365967 & 2306280 & 3672247 & $1,79 \%$ \\
\hline 14 & Chile & 2334421 & 1219747 & 3554168 & $1,73 \%$ \\
\hline 15 & Myanmar/Burma & 2150400 & 1048863 & 3199263 & $1,56 \%$ \\
\hline 16 & Thailand & 1479367 & 889891 & 2369258 & $1,15 \%$ \\
\hline 17 & Others & 25979066 & 7232834 & 33211900 & $16,17 \%$ \\
\hline & Total & $\mathbf{9 3 3 8 1 4 1 0}$ & $\mathbf{1 1 1 9 6 5 4 7 1}$ & $\mathbf{2 0 5 3 4 6 8 8 1}$ & $\mathbf{1 0 0 , 0 0 \%}$ \\
\hline
\end{tabular}

The quantity of fish only, produced from aquacultures for the period 2010-2019 in Bulgaria is presented on fig. 1 . In the period reviewed the quantity of fish from aquacultures has increases from 8878 tonnes to 13495 tonnes, which is 52\% more than in 2010 . At the same time, for 2019 , the total catch of fish and other water organisms, done by the Black sea fleet is $10269 \mathrm{t}$., and in the Danube - 60,717 t.

Table 2. EU producers catches fish and aquaculture (volume in tonnes live weight), for 2017

\begin{tabular}{|c|c|c|c|c|c|}
\hline No & Country & Catches & \% Volume & Aquaculture & \% Volume \\
\hline 1 & ES & $\mathbf{9 0 8} \mathbf{1 6 1 , 8 3}$ & $\mathbf{1 6 , 7 3 \%}$ & 314957 & $22,96 \%$ \\
\hline 2 & DK & 904572,00 & $16,66 \%$ & 34850 & $2,54 \%$ \\
\hline 3 & UK & 723306,25 & $13,32 \%$ & 222249 & $16,20 \%$ \\
\hline 4 & FR & 530474,15 & $9,77 \%$ & 189482 & $13,81 \%$ \\
\hline 5 & NL & 363097,22 & $6,69 \%$ & 51141 & $3,73 \%$ \\
\hline 6 & DE & 248178,82 & $4,57 \%$ & 33784 & $2,46 \%$ \\
\hline 7 & IE & 246823,57 & $4,55 \%$ & 43247 & $3,15 \%$ \\
\hline 8 & SE & 232632,79 & $4,29 \%$ & 14793 & $1,08 \%$ \\
\hline 9 & PL & 225225,45 & $4,15 \%$ & 36506 & $2,66 \%$ \\
\hline 10 & IT & 196002,60 & $3,61 \%$ & 156307 & $11,39 \%$ \\
\hline 11 & FI & 190375,74 & $3,51 \%$ & 14584 & $1,06 \%$ \\
\hline 12 & PT & 173601,63 & $3,20 \%$ & 12553 & $0,91 \%$ \\
\hline 13 & LV & 118139,37 & $2,18 \%$ & 808 & $0,06 \%$ \\
\hline 14 & EE & 82684,38 & $1,52 \%$ & 870 & $0,06 \%$ \\
\hline 15 & EL & 78288,93 & $1,44 \%$ & 125640 & $9,16 \%$ \\
\hline
\end{tabular}




\begin{tabular}{|c|c|c|c|c|c|}
\hline 16 & LT & 73235,92 & $1,35 \%$ & 3407 & $0,25 \%$ \\
\hline 17 & HR & 69934,07 & $1,29 \%$ & 17114 & $1,25 \%$ \\
\hline 18 & BE & 24649,30 & $0,45 \%$ & 75 & $0,01 \%$ \\
\hline 19 & RO & 14998,18 & $0,28 \%$ & 12798 & $0,93 \%$ \\
\hline $\mathbf{2 0}$ & BG & $\mathbf{8 5 5 8 , 8 1}$ & $\mathbf{0 , 1 6 \%}$ & $\mathbf{1 5 7 5 1}$ & $\mathbf{1 , 1 5 \%}$ \\
\hline 21 & HU & 5607,00 & $0,10 \%$ & 18258 & $1,33 \%$ \\
\hline 22 & CZ & 3557,00 & $0,07 \%$ & 21685 & $1,58 \%$ \\
\hline 23 & MT & 2223,17 & $0,04 \%$ & 15721 & $1,15 \%$ \\
\hline 24 & SK & 1870,00 & $0,03 \%$ & 2609 & $0,19 \%$ \\
\hline 25 & CY & 1756,41 & $0,03 \%$ & 7276 & $0,53 \%$ \\
\hline 26 & AT & 350,00 & $0,01 \%$ & 3863 & $0,28 \%$ \\
\hline 27 & SI & 265,60 & $0,005 \%$ & 1684 & $0,12 \%$ \\
\hline & Total EU-27 & $\mathbf{5 4 2 8} \mathbf{5 7 0}$ & $\mathbf{1 0 0 , 0 0 \%}$ & $\mathbf{1 3 7 2} \mathbf{0 1 2}$ & $\mathbf{1 0 0 , 0 0 \%}$ \\
\hline
\end{tabular}

It should be taken into consideration that according to the data for 2018, the companies for ocean and sea fishing, as well as those for sweet water fishing in our country are 76 in total with over $95 \%$ of the ocean and sea fishing and $100 \%$ sweet water fishing microcompanies with up to 9 employees [10].

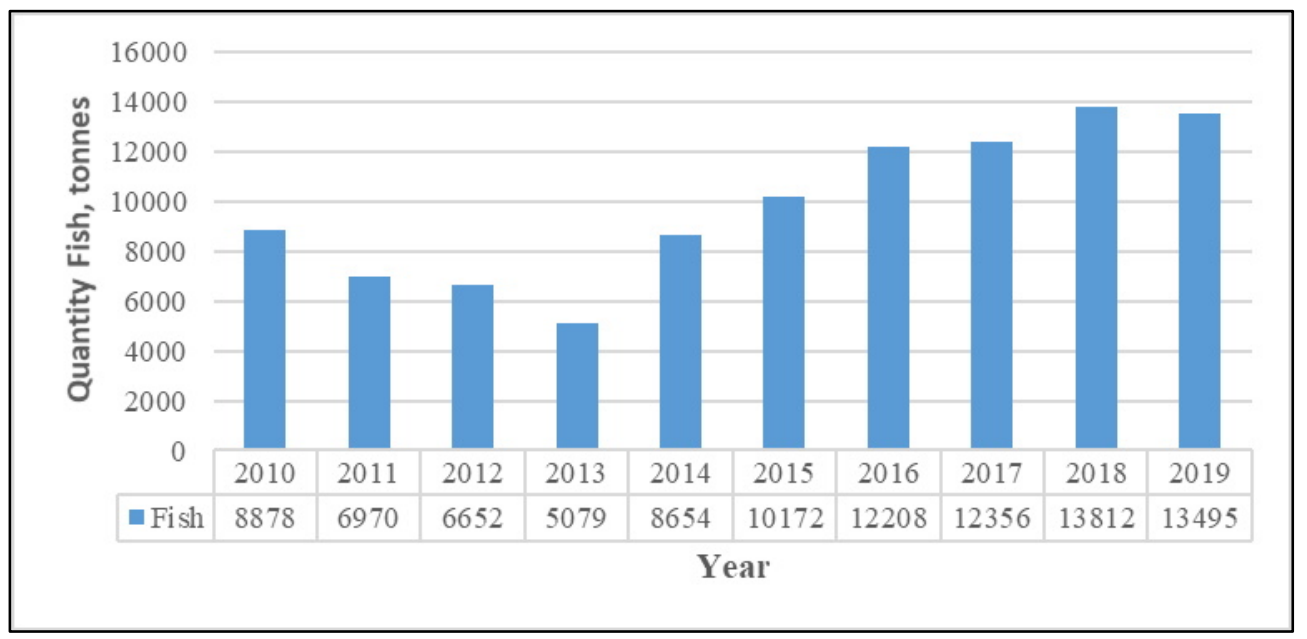

Fig 1. Bulgarian producers fish from aquaculture (volume in tonnes live weight), for 2010-2019

The companies which breed fish and other water organisms in aquacultures for 2019 are 745 in total, with 717 of them for sweet water fish. The types of fish and other water organisms bred in the country in 2019 are 37 , with the largest share of $60,1 \%$ for carp fish, $31,4 \%$ for trout, $3,9 \%$ car fish and 3,4\% sturgeon fish [10].

The quantity of caught and processed fish in the country is not sufficient to satisfy the needs of the Bulgarian market since the consumption of fish and fish products for the period $2013-2017$ was from 6,7 to $4,9 \mathrm{~kg} /$ person and the government aims to increase that amount. The total amount of fish and water organisms caught, 24310 tons, shows that the annual average is $3,47 \mathrm{~kg} /$ person, with over $4,9 \mathrm{~kg} /$ person reported consumption. In relation to this, Bulgaria imports fish and fish products from other countries, which is twice as large as the local production, which for 2017 was 43379 tons [11]. The import is mainly from Romania, 
Spain, the Netherlands, Greece, Denmark, Poland, and Latvia. Simultaneously, there is an export of 19459 tons. In this way, an annual average of 7,48 kg/ person is provided, which is in compliance with the policy for increasing the consumption of fish in the next years. The data show that there are perspectives in the country for the producers and processing companies, related to increased production and supply of fish and fish products in the retail chain. For this purpose, the Multi-annual national strategic plan for aquacultures in Bulgaria for 2021-2027 includes promoting high awareness of the general public and sales through online shops, mobile shops, farmers' markets [12].

\subsubsection{Specific features of fish farming and transportation}

The technologies for fish breeding are among the fastest developing innovations implemented in food production. They allow, in some cases, fish to be bred in domestic-like conditions, thus becoming an environment easy to use.

The main concept of fish breeding in small quantities is the combination of aquaculture with hydroponic technology in one system [13]. The technology for aquaponic breeding is applicable in domestic conditions as well. The aquaponic fish breeding system can reduce the use of land while increasing the efficient use of nutrients from the remaining part of the fodder [14].

Aquaponics is a mixture of a hydroponic or aeroponic system of plant growing and fish breeding aquaculture in one system. In Indonesia this system is implemented in a sweet water system with a closed cycle [15], where plants and fish grow together in symbiosis [16].

The aquaponic system combines two methods of recirculation of agriculture production of aquaculture and hydroponics [17]. The technology is a closed system of plants in accordance with the conditions for plant growth [18].

Using temperature sensors in this system is necessary in order to know at all times he increases and decrease of water temperature, which must subsequently be immediately regulated and maintained within the necessary limits for breeding according to the habitat of the fish species concerned [19]. This solution is achieved through using an intelligent information system.

Another innovative system for fish breeding is Aquafish. This is a system with closed water exchange for intensive fish breeding in domestic conditions with subsequent sale. The system provides for breeding and selling from $800 \mathrm{~kg}$ to 100 tons of fish annually.

Storing the fish during transportation is a serious problem of fish trading for two main reasons: the conditions during transportation from the fish farm to the processing plant and then to the retailer warehouse. In this period the fish may be damaged, killed or get serious stress. In this respect, rules for transportation have been introduced, which include the quantity and quality of water, where the live fish is placed, the type of tank, the quantity of oxygen, etc.

Fish transport is short-term and long-term. The short-term can last from 1 to 3 hours. In this case, the fish consumes less oxygen because its metabolism is reduced. With the longterm transport, the amount of oxygen needed should be considered.

Fish transport also depends on the temperature of the environment. When the weather is warm and the temperatures high, there should be considered some cooling with cold water, ice or air-conditioning. When the weather is cold, the water used should have the same temperature as that of the water in the container where the fish is stored before transportation.

\subsection{Technology for securing fish stocks}

Basically, the scheme for providing the warehouses for processing and the storage in the fish shop network can be presented with the following flow chart, fig.2. 


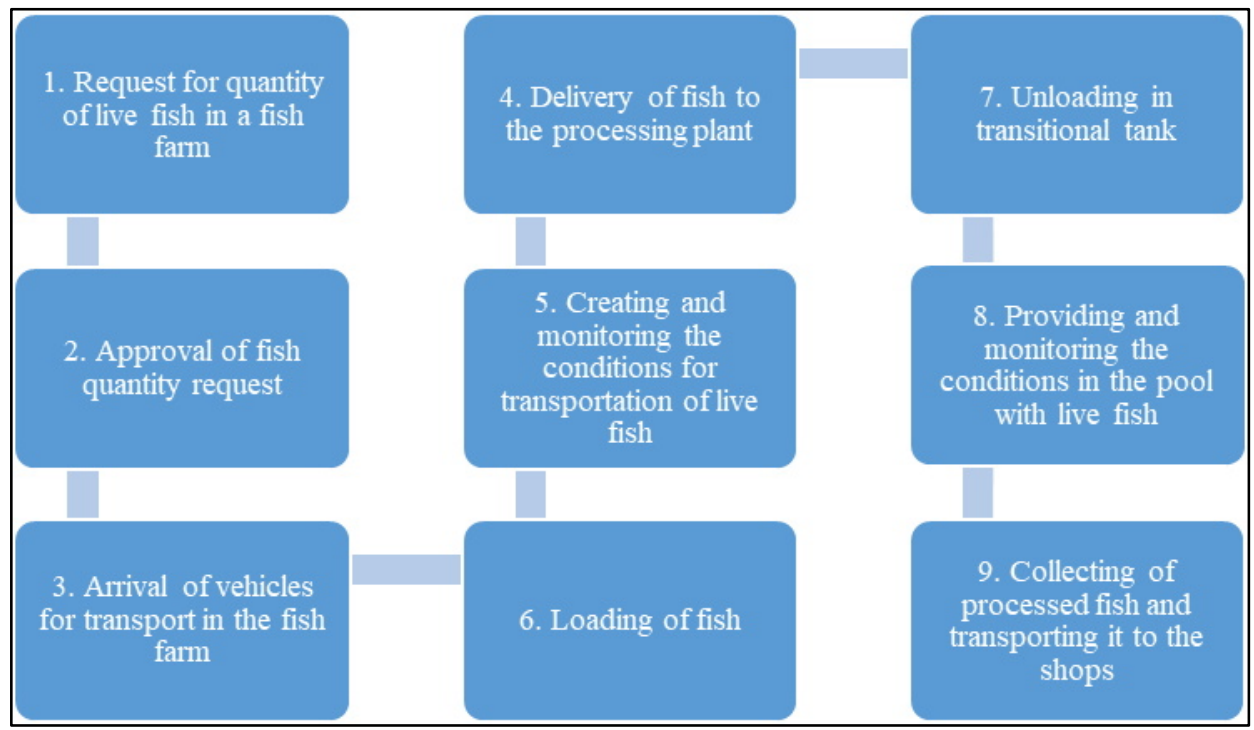

Fig. 2. Flow chart for providing transitional and end storage of fish

The fish production process takes place in freshwater or saltwater (sea) reservoirs or fish farms. In recent years, due to the increased consumption of fish products, the production of fish in aquaculture has also increased [11]. This report examines the processes that take place during the supply of live fish produced from freshwater sources in the country to end customers. Usually, this fish weighs from 200 grams to $50 \mathrm{~kg}$ and includes carp, silver carp, catfish, grass carp, white fish, pike and sometimes small fish and sturgeon. The process, at certain fish prices, proceeds in the following sequence:

1) first the fish farm receives a request to provide a certain quantity $Q_{1}$ of fish;

2) The fish farm checks for availability of requested quantity and sends an answer $Q_{2}$ about the quantity of fish they can provide, which can be:

- Variant one $Q_{2}<Q_{1}$;

- Variant two $Q_{2}=Q_{1}$, this is the best case.

If $Q_{2}<Q_{1}$, then the ordering party may cancel the order and look for another fish producer. If, however, the demand for fish is high while the quantities available are small, then the offer can be approved, and a vehicle can be sent to the respective fish farm for it. In the second variant, when $Q_{2}=Q_{1}$ the offer is approved directly, and a vehicle is sent for the fish.

3) The vehicle prepared for the transportation of the fish arrives at the fish farm to be loaded with the quantity determined, fig.3.

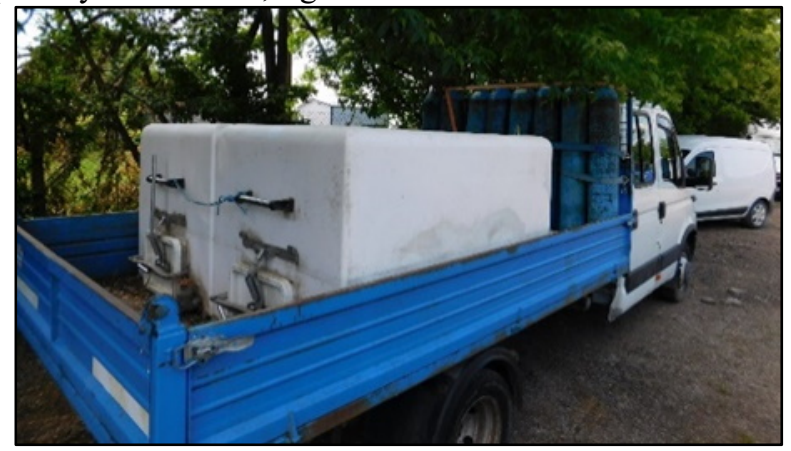

Fig. 3. General type of means of transport for live fish 
There are water tanks in the vehicle, where the live fish is placed. In order for the fish to stay live during transportation, it is provided with a normal environment that must meet certain regulatory requirements shown in $[5,6]$. Often these conditions are difficult to comply with because in the country the ambient temperature varies widely, reaching values above $30-35^{\circ} \mathrm{C}$ in summer, and under minus $10-15^{\circ} \mathrm{C}$ in winter, with even bigger values at certain points of the day [7]. Therefore, it is good to keep the temperature within certain normal limits. It is also important to provide oxygen in the fish tanks from an additional system with oxygen cylinders, which is often regulated by the driver, depending on his experience and observation. Finally, it is possible to indicate the tightness of the tank with water and fish, which can be damaged during transportation by shaking or by natural factors related to the material of the tank and its lids. In order to comply with these requirements, it is necessary to have a system for monitoring, signaling and control.

4) Choice of delivery route. Usually, this is the most frequently used road, where the vehicles will take the shortest time to reach their destination. Sometimes, there are cases of random incidents along the way such as accidents, floods, protests and others, which obstruct the use of this route. Navigation and vehicle location information system may be used for this purpose during transportation.

5) Unloading in transitional reservoirs of the processing company. The unloading takes place directly from the vehicle after opening the sluices of the tanks fig.3. Here, when the water and the fish flow through the opening of the tanks, the fish can be injured, and with the seasonal differences in the temperature of the environment, conditions can be created for the stress of the fish.

6) The fish is unloaded in tanks, which are prepared in advance to take the entire amount of fish delivered. They meet the requirements for the quality of living conditions of fish. The water they are filled with is extracted from boreholes, in order to have a normal temperature. These tanks are usually used for a short stay of the fish up to one week, which is why they are in open air lots. Sometimes, however, due to a lack of continuous control, the quality of the environment may deteriorate and dead fish may appear, fig.4.

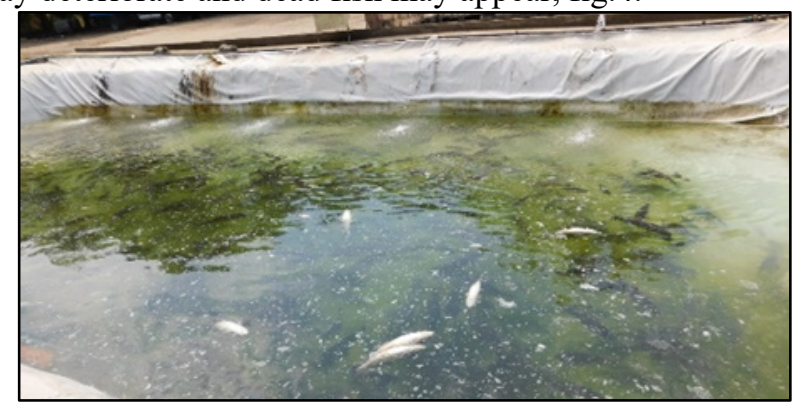

Fig. 4. Transitional storage for preservation of live fish

In these transitional tanks, there is an additional system for oxygen and fresh water provided for the fish. The fish that is to be processed and then sent to the shops is not fed normally. Due to the influence of the external environment, it is appropriate to put in these tanks an information system with sensors, to provide information on the presence of oxygen, carbon dioxide, ammonia and water temperature.

7) Processing of live fish in the plant. Before subsequent processing, the fish is killed in one of the ways, specified in the regulations (killing by electricity, blow to the head, or cooling in refrigerators). The safe method of cooling is often applied. The killed fish can then: be prepared for the next transport to the store net, chilled and placed in ice trays; clean, cut and chilled in ice to prepare it for sale; cleaned and processed by performing any of the following procedures: smoking in chambers (hot, cold). All these operations are performed 
in professional chambers with a system for management, control, and monitoring. There is no need to introduce new systems, with the exception of those that are not connected in a unified network for general management and control. The quantity of fish that is processed is in accordance with the orders received for delivery of finished processed fish products in quantities $Q_{i}$.

8) Fish in stock. There are almost no quantities of processed fish stored in the warehouses of the processing plants, except those, for which the temperature regime should be maintained, or those, which are to be taken with a delay of one or two days due to holidays, weekends, or other force majeure circumstances. Such would be smoked, sliced and chilled uncleaned fish prepared for sale.

9) Delivery to retailers. The delivery is carried out according to a preliminary request and a contract with the fish farm. The transport is performed by carriers that have been authorized for such type of transportation, using appropriate and approved vehicles with controlled temperature (chilled, frozen fish), or provided with specialized baths or troughs where the fish is placed in ice.

10) Warehouses in retail shops. Here the fish products and the fish itself are placed in the glass showcases and, in the warehouses, meeting the requirements for trade in fish of the country, according to the normative requirements of the country and the instructions of the Bulgarian Food Safety Agency.

11)End consumers. This is the last unit, which can be a food chain, a restaurant, or a private person, etc.

\subsection{A system for intelligent monitoring of the process of securing fresh fish stocks from freshwater fish farms}

The options for an intelligent system for monitoring and managing the quality of the live fish environment are three:

Option 1 - serial connection of sensors for inspection and quality management of the environment with live fish;

Option 2 - parallel connection of sensors for inspection and quality management of the environment with live fish;

Option 3 - mixed connection of sensors for inspection and quality management of the environment with live fish.

Option 1 of a flow chart for control and management of the environment for transporting and storing the fish in the warehouse is presented on fig.5.

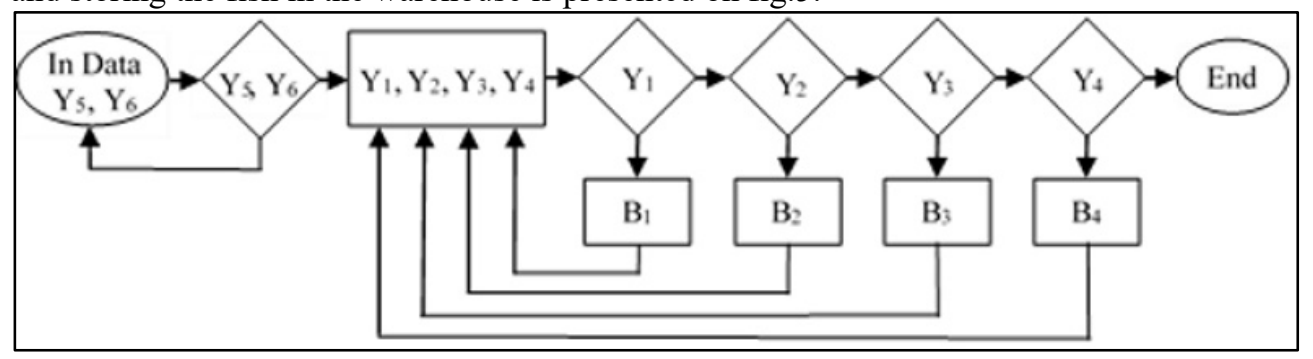

Legend:

$\mathrm{Y}_{1}$ - temperature monitoring on assignment, e.g. $\left(10-20^{\circ} \mathrm{C}\right) \mathrm{Y} 5.2-\mathrm{Y} 2<>\mathrm{B} 2$;

$\mathrm{Y}_{2}$ - oxygen monitoring on assignment (70-200\%) Y5.1 - Y1<>B1;

$\mathrm{Y}_{3}-\mathrm{pH}$ monitoring on assignment, e.g. (6.8-7.2) $\mathrm{Y} 5.3$ - $\mathrm{Y} 3<>\mathrm{B} 3$;

$\mathrm{Y}_{4}$-tank level monitoring on assignment (level sensor: 0-2 m) $\mathrm{Y} 5.4$ - $\mathrm{Y} 4<>\mathrm{B} 4$;

$\mathrm{Y}_{5}$ - water quantity in the tank, liters. Assigned in advance;

$\mathrm{Y}_{6}$ - fish quantity, $\mathrm{kg}$. Assigned in advance. It is $Q_{2}$;

$\mathrm{B}_{1}$ - Oxygen enrichment system; 


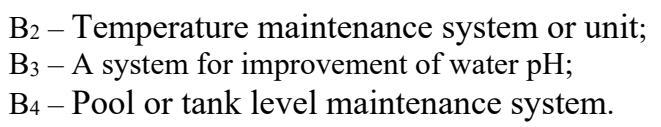

Fig. 5. Flow chart for control and monitoring of the conditions in the fish environment during transportation or storage in the warehouse with serial connection of the sensors

The flow chart on fig. 5 presents how the intelligent system for monitoring and quality control of the environment in which live fish is stored works. These are warehouses for transitional storage of fish and tanks for storage of live fish during transportation from fish farms to processing plants. When the system is turned on, it starts monitoring each of the four indicators one by one, according to the priority given. In this case, it is conditionally set that it is monitored first $\mathrm{Y}_{1}-$ the temperature. If it is not in the limits, then it is signaled and $\mathrm{B}_{1}-$ the temperature maintenance system or unit is turned on. Once the temperature is within the required set limits, then the system moves on to monitoring the second indicator $\mathrm{Y}_{2}$ - oxygen. If it is not within the range, then it is signaled and $\mathrm{B}_{2}-$ the oxygen enrichment system is turned on. Once the oxygen is within the required range, then the system moves on to monitoring the third indicator $\mathrm{Y}_{3}-\mathrm{pH}$ monitoring, the last indicator $\mathrm{Y}_{4}-$ water level in the tank - is checked according to the same scheme. The last three indicators are interconnected, and their values are regulated by supplying fresh water to the tank. Therefore, it may turn out that when adjusting the second indicator $\mathrm{Y}_{2}$ their values are corrected too. The change in the values of these three indicators also affects the first indicator $\mathrm{Y}_{1}$. In this regard, the values of the four indicators should be monitored simultaneously. In this case, the scheme turned out to be inappropriate and was rejected.

Option 2 is presented on fig.6.

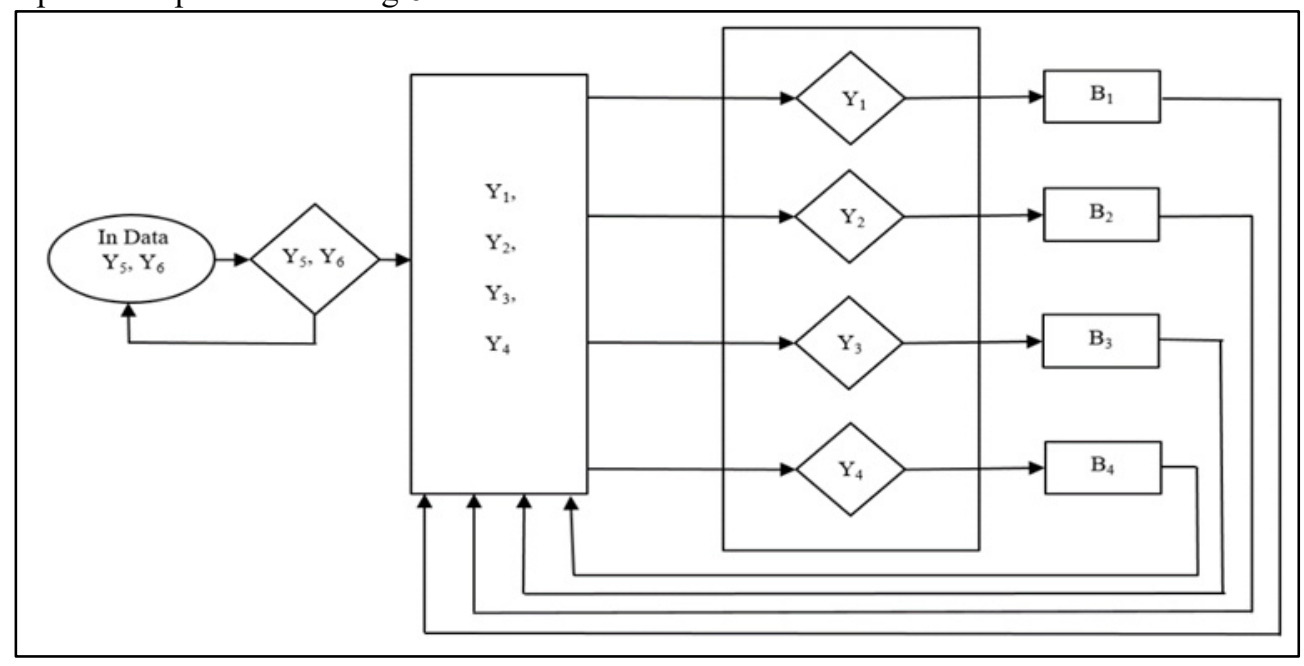

Fig. 6. Flow chart for control and monitoring of the conditions in the fish environment during transportation or storage in the warehouse with parallel connection of the sensors

With option 2, once the amount of fish has been placed in the tank water, the system immediately starts monitoring the four important indicators at the same time. ( $\mathrm{Y}_{1}, \mathrm{Y}_{2}, \mathrm{Y}_{3}$ and $\mathrm{Y}_{4}$ ). If it turns out that one of the indicators is not within the accepted limits, the relevant system is immediately switched on $\left(\mathrm{B}_{1}, \mathrm{~B}_{2}, \mathrm{~B}_{3}, \mathrm{~B}_{4}\right)$ and it starts working until the values of the indicator become within the accepted limits. It is possible to switch on all four systems at the same time to obtain the values of the indicators within the desired limits, if necessary. This option turns out to be suitable for the system, so it is accepted for implementation and the third option will not be considered. 


\subsection{Mathematical model}

Adequate regression models have been derived for the above-mentioned properties Temperature - Tv, the relative the amount of oxygen $-\mathrm{O}_{2} \mathrm{v}$ and the connected $\mathrm{pH}$ based on 30 different combinations of these parameters using an experimental design and a statistical method described in [20] and in [21].

In Table 3 the four parameters with their indicative limit values are given. It can be seen that the interval of their change is quite large, so an appropriate calculation approach should be created, in order to easily identify trends in the change of values of indicators with a starting point, presented as a percentage of the minimum or maximum value.

When deriving the equations for the quality of the medium, it is taken into account that all parameters from x1-x4 for models (1) - (4) are the same. The structure of all regression models 1-4 has been chosen in such a way that the difference between the forecast and experimental data are the smallest. All this has been based by standard statistical adequacy checks.

Table 3. Intervals of change of the fourth parameters

\begin{tabular}{|c|c|c|c|c|}
\hline \multirow{3}{*}{ № } & \multirow{3}{*}{ Parameters } & Extreme low & Average & Extreme high \\
\hline & & \multicolumn{3}{|c|}{ Interval value of mode change } \\
\hline & & Code $[-1]$ & Code [0] & Code [+1] \\
\hline 1 & Temperature $\mathrm{t}\left[{ }^{\circ} \mathrm{C}\right]-\left(\mathrm{X}_{1}\right)$ & 5 & 12.5 & 20 \\
\hline 2 & The amount of oxygen $\mathrm{O}_{2} \mathrm{v}[\%]-\left(\mathrm{X}_{2}\right)$ & 70 & 135 & 200 \\
\hline 3 & Water hardness $[\mathrm{pH}]-\left(\mathrm{X}_{3}\right)$ & 6.8 & 7 & 7.2 \\
\hline 4 & The maintained level $\mathrm{h}_{\mathrm{m}}[\mathrm{m}]-\left(\mathrm{X}_{4}\right)$ & 1 & 1.5 & 2 \\
\hline
\end{tabular}

When developing the model, it is assumed that the water level in the pool is constant or varies from 1 to $2 \mathrm{~m}$. In addition, it is assumed that the change in all indicators is linear. Therefore, equations of only the first three indicators are presented. After processing preset sample data for simulation in a software product MiniTAB the following equations are obtained:

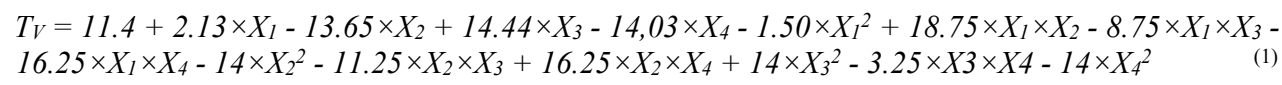

$O_{2} v=0.4020-0.0828 \times X_{1}+0.0033 \times X_{2}-0.0523 \times X_{3}-0.0008 \times X_{4}+0.0037 \times X_{I}^{2}+0.0106 \times X_{1} \times X_{2}$ $+0.0244 \times X_{1} \times X_{3}-0.0006 \times X_{1} \times X_{4}+0.0087 \times X_{2}^{2}-0.0469 \times X_{2} \times X_{3}+0.0031 \times X_{2} \times X_{4}+0.0237 \times X_{3}^{2}+$ $0.0093 \times X_{3} \times X_{4}+0.0512 \times X_{4}^{2}$

$$
\begin{aligned}
& p H=6.9+2.47 \times X_{1}+0.92 \times X_{2}+1.47 \times X_{3}-0.8 \times X_{4}-1.13 \times X_{1}^{2}+0.44 \times X_{1} \times X_{2}-0.06 \times X_{1} \times X_{4}- \\
& 0.88 \times X_{2}^{2}+0.437 \times X_{2} \times X_{3}-0.19 \times X_{2} \times X_{4}-0.13 \times X_{3}^{2}+0.31 \times X_{3} \times X_{4}-0.88 \times X_{4}^{2}
\end{aligned}
$$

All this is justified by standard statistical adequacy checks. These parameters are coded with 1, 2 and 3 depending on whether the obtained after processing the obtained layer with $\mathrm{B}_{1}, \mathrm{~B}_{2}$ and $\mathrm{B}_{3}+\mathrm{B}_{4}$. This equation has the form:

$F\left(B_{1}, B_{2}\right.$ and $\left.B_{3}+B_{4}\right)=2.01825+0.05025 \times X_{1}+0.17525 \times X_{2}+0.37079 \times X_{3}-0.0270649 \times X_{1}^{2}-$ $0.0405855 \times X_{1} \times X_{2}+0.125 \times X_{1} \times X_{3}+0.5 \times X_{1} \times X_{4}+0.0613369 \times X_{2}^{2}-0.125 \times X_{2} \times X_{4}+0.0452575 \times X_{3}^{2}$ $+0.125 \times X_{3} \times X_{4}$.

For this regression model, the standard checks were also performed for the coefficient of determination $\mathrm{R}=0.9131$, as well as for the calculated value according to Fisher's criterion, 
which is 5.0143 and it is greater than that in the table 2.5802, [22]. This is proof that the model is adequate and can be used for subsequent calculations.

\subsection{Expected results}

In the presented model with equations 1-4 a simulation was made with the software product MiniTAB and solutions were obtained for appropriate values of the three studied indicators, where the quality of the environment will be the best for live fish, Fig.7. In Fig. 7 the colored area with dark yellow color shows the area with the highest quality $90-100 \%$ of the water in the pool. In this case, it revolves around indicator $\mathrm{Y}_{2}$ - oxygen and the complex influence of other indicators.

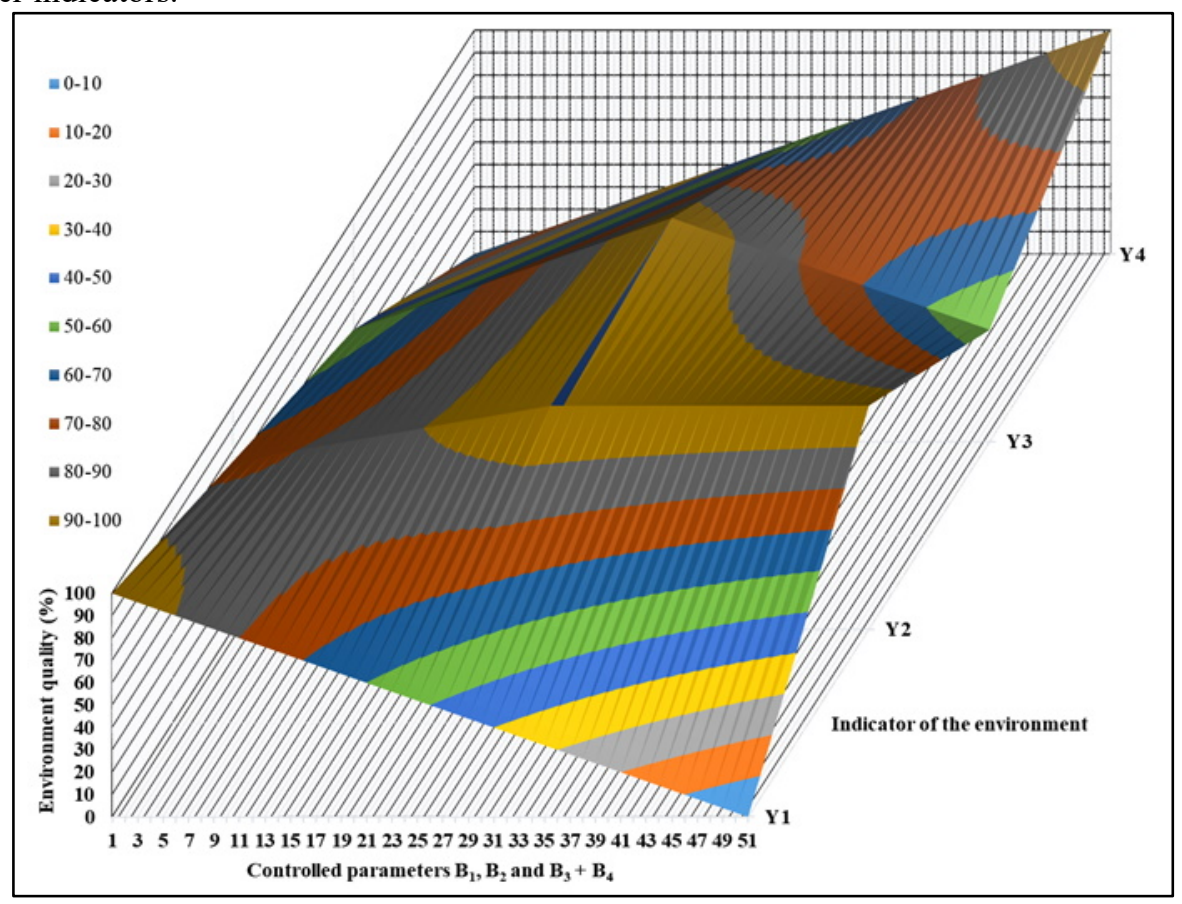

Fig 7. Result for expected quality environment for storage of live fish

On fig. 8 a transitional warehouse for live fish is shown. In this case, the environment quality corresponds to the requirements for preserving the fish alive, so no dead fish is observed. Besides, it is a sturgeon fish, which is quite expensive, and that is why the control is tighter. It is expected that the condition of the fish in all reservoirs will be like this after introducing the proposed intelligent system for monitoring, management and control of the quality of the environment with life fish. 


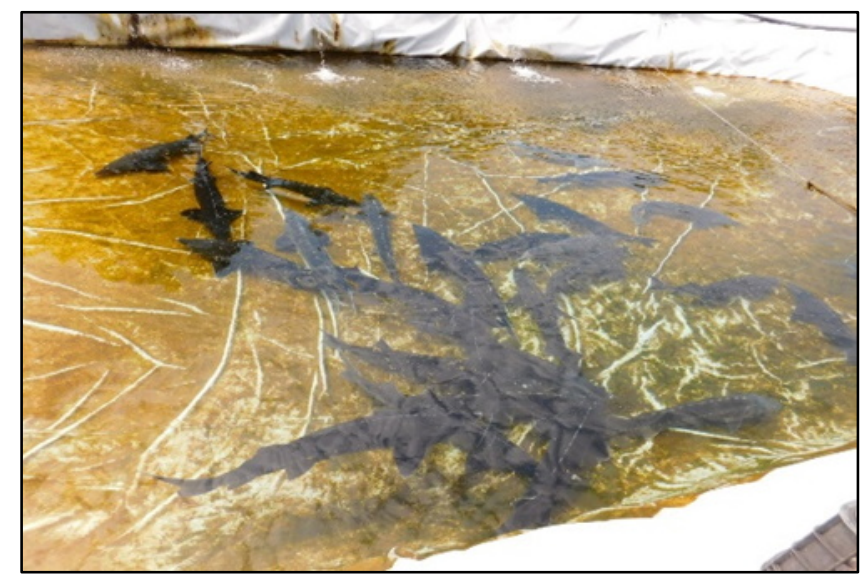

Fig 8. A transitional warehouse for live fish in quality environment

\section{Conclusion}

A study of the quantity of fish produced and imported into the Republic of Bulgaria for 2017 year has established that 15751 tons have been obtained from aquacultures, 8559 tons from catch in salt water and sweet water basins, including the Black Sea, the Danube River and domestic fish farms. The total amount of fish and aquatic products of 24310 tons shows that the yield is $3,47 \mathrm{~kg} /$ person in the country, which is insufficient since the average annual consumption in the country is over $4,9 \mathrm{~kg} /$ person. The difference is covered by the import of fish and fish products from other countries such as Romania, Spain, the Netherlands, Greece, Denmark, Poland and Latvia, and was doubled for 2017. In this way, the annual average provided is $7,71 \mathrm{~kg} /$ person, which corresponds to the government policy for increasing the fish consumption in the next years and demonstrates to the producers and processing companies that they can increase the production and supply of fish and fish products in the shops.

Some of the main problems faced mainly by fish farms in Bulgaria are related to the provision of a quality environment for the preservation of live fish before it is prepared for the network of shops. In connection with this, an intelligent information system has been proposed for implementation, which should monitor in real time the main indicators related to the quality of the environment for storing live fish. This system will act automatically on various mechanisms for ensuring these indicators within normal limits. In this way, the fish farm will be informed at any time about the quality of the environment, and fish mortality caused by human error is expected to be reduced to zero.

Some weak points have been found in the transitional warehouses. They are determined by the values of the four main indexes, namely oxygen, temperature, $\mathrm{pH}$ acidity and water level, when the quality of the environment in which the live fish is stored may be impaired. In connection with this was created a regression model with the four main indicators, which should be monitored and maintained within certain limits so as to obtain a high quality environment. A coefficient of determination $\mathrm{R}=0.9131$ and Fisher's criterion, which is 5.0143 , compared to the one in the table - 2.5802 were determined for the regression model. This shows that the model is adequate and can be used for further calculations.

The research leading to these results has received funding from the Ministry of education and science under the National science program "Intelligent animal husbandry", grant agreement $\mathrm{N}^{\circ}$ Д01$62 / 18.03 .2021$. 


\section{References}

1. OIE - Aquatic animal health code, Twenty-second Edition (2019), https://rreurope.oie.int/wp-content/uploads/2020/08/oie-aqua-code_2019_en.pdf

2. J. L. Saraiva, P. Arechavala-Lopez, M. J. Cabrera-Álvarez, D. Waley, Research for ANIT Committee - Particular welfare needs in animal transport: aquatic animals, European Parliament, Policy Department for Structural and Cohesion Policies, (Brussels, 2021)

3. Ministry of Agriculture, Food and Forestry, Strategy for digitalization of agriculture and rural areas of the Republic of Bulgaria, Sofia (2019)

4. Ministry of Agriculture, Food and Forestry, Fisheries and Aquaculture Act. (2019)

5. Scientific, Technical and Economic Committee for Fisheries (STECF) - The EU Fish Processing Sector, Economic Report (STECF-19-15), (Public. Office of the EU, Luxembourg, 2019)

6. Executive Agency for Fisheries and Aquaculture, National Strategic Plan for Fisheries and Aquaculture 2007-2013, Sofia, 82 (2006)

7. Strategic Planning Analysis Directorate, Situational-perspective analysis of fish and other aquatic organisms in 2017 and prospects for 2018, Sofia, 21 (2018)

8. M. Mulqan, S. A. El Rahimi, I. Dewiyanti, Jurnal Ilmiah Mahasiswa Kelautan dan Perikanan Unsyiah, 2(1), 183-193 (2017), ISSN 2527-6395

9. Y. Wihardi, I. A.Yusanti, dan R. B. Kusuma Haris, Jurnal Ilmu-ilmu Perikanan dan Budidaya Perairan, 9(1), 23-28 (2014)

10. T. S. Harmon, Int. J. Recirc. Aquac., 6, 13-22 (2005)

11. Y. Dhahiyat, A. Rizal, Zahidah, IJAER, 4(2), 412-419 (2018)

12. S. R. Surnar, O. P. Sharma, V.P. Saini, Int. J. Fish. Aquat. Stud., 2(4), 261-263, (2015)

13. D. Atia, H. T.El-madany, JESIT, 4(1), 33-48 (2017)

14. A. Indriani, J. Johan, Y. Witanto, H. Hendra, J. Mech. Eng, 5(2), 183-192 (2014)

15. Regulation 2004/853 - Specific hygiene rules for food of animal origin (2004) https://eur-lex.europa.eu/legalcontent/BG/TXT/PDF/?uri=CELEX:32004R0853\&from=BG

16. Bulgarian Food Safety Agency (BFSA), https://www.bfsa.bg

17. N. Tontchev, Materials science, Effective solutions and technological variants, (Lambert, Acad. Publ., 2014))

18. I. N. Vuchkov, I. I. Vuchkov, Statistical methods of quality control, robust engineering, planning, modeling and optimization, QStatLab, v 5.3, (2009)

19. S. K. Stoyanov, Methods and algorithms for fast convergence, Thesis for D Sc, Chemical Technology and Metallurgy, Sofia, Bulgaria (1990)

20. Ministry of Agriculture, Food and Forestry, Fisheries and Aquaculture Act. (2018), http://iara.government.bg/wpcontent/uploads/2018/08/ZAKON za ribarstvoto i akvakulturite.pdf

21. Ministry of Agriculture, Food and Forestry, Situational analysis of the state of the fisheries sector in Bulgaria, Sofia (2021), https://www.eufunds.bg/en/node/6970

22. T. Hubenova, E. Uzunova, A. Zaykov, Y. Markov, S. Delcheva, Multiannual National Strategic Plan for Aquaculture in Bulgaria (2021-2027), 151 (2020), https://www.eufunds.bg/en/node/5871 